\title{
Erratum to: Palliative Interventional Pulmonology Procedures in the Incarcerated Population with Cancer: A Case Series
}

\author{
Samira Shojaee - Janet Dawson - Ray W. Shepherd • \\ Hans J. Lee
}

Published online: 11 February 2015

(C) Springer Science+Business Media New York 2015

Erratum to: Lung (2014) 192:915-920

\section{DOI 10.1007/s00408-014-9621-6}

Unfortunately, the abbreviated names of the authors were listed in the original publication. The complete names of all the authors are corrected with this erratum.

The online version of the original article can be found under doi:10.1007/s00408-014-9621-6.

S. Shojaee $(\bowtie) \cdot$ J. Dawson · R. W. Shepherd

Interventional Pulmonology, Pulmonary Disease and Critical

Care Medicine, Virginia Commonwealth University,

PO Box 980050, Richmond, VA 23298, USA

e-mail: sshojaee@mcvh-vcu.edu

J. Dawson

e-mail: jdawson@mcvh-vcu.edu

R. W. Shepherd

e-mail: rshepherd@mcvh-vcu.edu

H. J. Lee

Interventional Pulmonology, Pulmonary Disease and Critical

Care Medicine, The Johns Hopkins Hospital, 600 N. Wolfe

Street, Baltimore, MD 21287, USA

e-mail: hlee171@hjmi.edu 